\title{
Formation of Cold-Sprayed Ceramic Titanium Dioxide Layers on Metal Surfaces
}

\author{
J.-O. Kliemann, H. Gutzmann, F. Gärtner, H. Hübner, C. Borchers, and T. Klassen
}

(Submitted May 10, 2010; in revised form September 16, 2010)

\begin{abstract}
Titanium dioxide $\left(\mathrm{TiO}_{2}\right)$ coatings have potential applications in biomedical implants or as photo-catalytic functional systems. Cold spraying is a well-established method for metal on metal coatings. In cold spraying, the required heat for bonding is provided by plastic deformation of the impacting ductile particles. In contrast, few authors have investigated the impact phenomena and layer formation process for spraying brittle ceramic materials on ductile metal surfaces. In this study, the formation of $\mathrm{TiO}_{2}$ coatings on aluminum, copper, titanium, and steel substrates was investigated by SEM, TEM, XRD, and Raman spectroscopy. The results show that the deposition efficiency depends on spray temperature, powder properties, and in particular on substrate ductility, even for impact of ceramic particles during a second pass over already coated areas. Ceramic particles bond to metallic substrates showing evidence of shear instabilities. High-resolution TEM images revealed no crystal growth or phase transitions at the ceramic/metal interfaces.
\end{abstract}

Keywords bonding mechanism, cold spraying, photocatalytic activity, titanium dioxide

\section{Introduction}

Since its invention in 1986 by Anatoli Papyrin and his team (Ref 1), cold gas spraying has developed from a niche laboratory method of material deposition to a widely accepted spray technique with manifold applications. For metallic materials, bonding mechanisms are fairly well understood (Ref 2-4). Cold gas spraying is based on an acceleration of particles in a gas stream to high velocities of up to $1200 \mathrm{~m} / \mathrm{s}$. As opposed to conventional thermal spray techniques, process gas temperatures are low enough and exposure time to the hot gas stream is short enough to avoid melting of the particles. Bonding of cold-sprayed particles occurs when the particles impact with high velocities on the substrate. The resulting shear

This article is an invited paper selected from presentations at the 2010 International Thermal Spray Conference and has been expanded from the original presentation. It is simultaneously published in Thermal Spray: Global Solutions for Future Applications, Proceedings of the 2010 International Thermal Spray Conference, Singapore, May 3-5, 2010, Basil R. Marple, Arvind Agarwal, Margaret M. Hyland, Yuk-Chiu Lau, Chang-Jiu Li, Rogerio S. Lima, and Ghislain Montavon, Ed., ASM International, Materials Park, OH, 2011.

J.-O. Kliemann, H. Gutzmann, F. Gärtner, H. Hübner, and T. Klassen, Helmut Schmidt University, University of the Federal Armed Forces, Holstenhofweg 85, 22043 Hamburg, Germany; and C. Borchers, Institut für Materialphysik, Georg August University of Göttingen, Göttingen, Germany. Contact e-mail: kliemann@hsu-hh.de. stresses lead to plastic deformation. Kinetic energy is converted to thermal energy, which cannot dissipate within the short time frame of the impact (quasi-adiabatic conditions). Metallic materials soften at the boundaries, which leads to more plastic deformation and heat generation, resulting in shear instabilities. Basic principles can also be transferred to cold spraying of metals on ceramic substrates and the deposition of metal ceramic composite layers (Ref 5-7). For these examples, it can be assumed that bonding occurs if one ductile component attains shear instabilities by plastic deformation. So far only few authors have investigated the kinetic impact of pure ceramic particles on metal surfaces. This is not surprising. The above-mentioned process based on plastic deformation does not work with brittle reaction partners. A brittle ceramic would not go through plastic deformation, it would rather break. Nevertheless, it is possible to spray ceramic particles onto metallic substrates. Li et al. (Ref 8) and others (Ref 9) have shown that it is possible to spray $\mathrm{TiO}_{2}$ with high photocatalytic activities using cold gas spraying, but coating thicknesses were limited to $10 \mu \mathrm{m}$ using agglomerated nanopowders. Other research has reported the possible build-up of thick ceramic/titania coatings with aerosol spraying (Ref 10), vacuum cold spraying (Ref 11) and recently also high pressure cold spraying (Ref 12). However, the bonding mechanism is still unknown. Mechanical compaction and entanglement by the later impacting particles (Ref 11) and chemical formation (Ref 10,12) have been proposed.

In this study, we report on requirements for bonding ceramic particles on metallic substrates in cold spraying, with titanium dioxide $\left(\mathrm{TiO}_{2}\right)$ as a model system. In contrast to former studies (Ref 10-12), dense $\mathrm{TiO}_{2}$ anatase particles with nanosized crystallites were used to investigate the coatings build-up. $\mathrm{TiO}_{2}$ is of special interest because of its photocatalytical properties which have been 
electrochemically explored by Fujishima and Honda (Ref 13). This article focuses on the coating creation and crystallographic structures of the cold-sprayed coatings. Data on the photocatalytic activity of the cold-sprayed coatings in comparison with other thermal spray technologies has been reported elsewhere (Ref 14).

\section{Experimental Procedures}

In this study, anatase $\mathrm{TiO}_{2}$ powder was cold-sprayed onto four different metal substrate types: pure titanium, stainless steel (EN 1.4301, AISI 304), copper, and an aluminum alloy (AlMg3). All coatings were sprayed with a CGT Kinetiks 4000 system with nitrogen as process gas. The traverse speed of the spray gun was kept constant at $320 \mathrm{~mm} / \mathrm{s}$. The powder feed rate was kept constant at $0.22 \mathrm{~g} / \mathrm{s}$. An anatase $\mathrm{TiO}_{2}$ Hombikat TS40 provided by Sachtleben, Germany, served as powder feedstock. The powder was tempered for $3 \mathrm{~h}$ at $600{ }^{\circ} \mathrm{C}$ in air atmosphere before spraying. The spray parameters are listed in Table 1.

Particle velocities were measured by a Tecnar ColdSpray Meter. Powder morphologies and layer cross sections were investigated by optical microscopy (OM) and scanning electron microscopy (SEM) in as-polished conditions. Specimen for TEM were prepared with a focused ion beam (FIB) FEI Nova 600 Nano Lab with electron optics operated at $5 \mathrm{kV}$, sample preparation done with $30 \mathrm{kV}$ Ga-ions, and last finish with $5 \mathrm{kV}$ Ga-ions. Samples were prepared from cross sections of the coatings. SEM was performed with a PHILIPS CM 200 UT-FEG operated at $200 \mathrm{kV}$, and a PHILIPS CM 30 operated at $300 \mathrm{kV}$. Micro-Raman spectroscopy was used to detect possible phase transitions in the sprayed coatings. The mass gain was measured by weighing the substrate before and after the coating process. The deposition efficiency was determined as the ratio between the deposition rate and the powder feed rate.

\section{Experimental Results}

\subsection{Powder Feedstock}

The micrographs in Fig. 1 display the powder morphologies and the microstructures of an as-polished powder cross section, and show that the powder is spherical. The powder size distribution ranges from about 3 to $50 \mu \mathrm{m}$ and includes a rather high amount of fines. Tempering of

Table 1 Process parameters used in this study for cold spraying of $\mathrm{TiO}_{2}$ layers

\begin{tabular}{lcc}
\hline Temperature, ${ }^{\circ} \mathbf{C}$ & Gas pressure, bar & Spray distance, mm \\
\hline 200 & 30 & 60 \\
400 & 30 & 60 \\
600 & 40 & 60 \\
800 & 40 & 60 \\
\hline
\end{tabular}

the Hombikat TS40 powder leads to a twofold effect: the open surface (measured via BET absorption) decreases from 250 to $60 \mathrm{~m}^{2} / \mathrm{g}$ (manufacturer data). An estimation of grain sizes according to the Scherrer formula based on peak broadening (full width at half maximum) of characteristic XRD peaks shows that the primary particle size increases from 5 to $15 \mathrm{~nm}$. The cross section in Fig. 1 in particular reveals that the agglomerated powder looks rather dense due to the manufacturing and tempering process. Nevertheless, the powder hardness only reaches

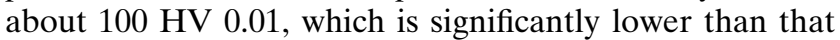
of bulk $\mathrm{TiO}_{2}$ single crystals [5.5-6.0 Mohs corresponding to $670-800 \mathrm{HV}(\operatorname{Ref} 15)]$.

\subsection{Cold Spraying and Particle Velocities}

During cold spraying, particle velocities were subsequently monitored. For the selected parameter set, substantially different mean particle velocities ranging from 590 to $833 \mathrm{~m} / \mathrm{s}$ were obtained (Table 2).

\subsection{Layer Deposition}

Figure 2 shows the results from the layer deposition on aluminum substrates. The amount of deposited $\mathrm{TiO}_{2}$ on aluminum is continuously rising with every pass, but the slope is decreasing with every additional pass, i.e., the
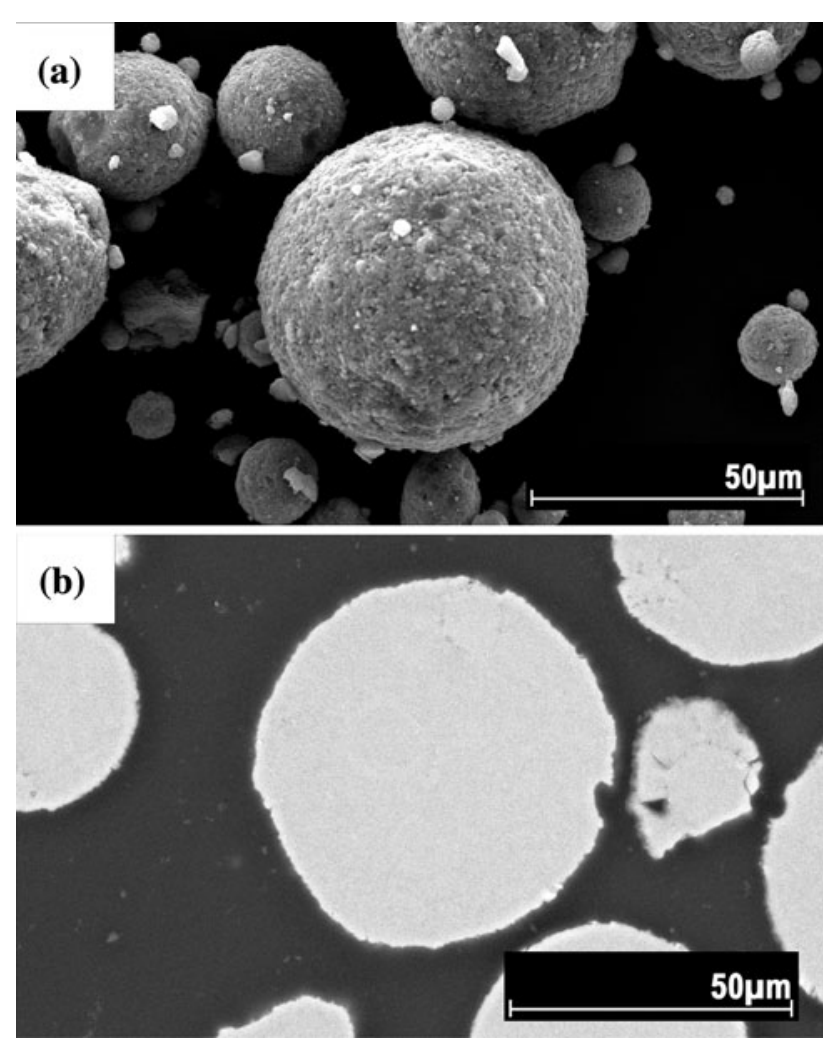

Fig. 1 SEM image of the powder morphology (a) and a cross section of the powder particles (b) of tempered Sachtleben Hombikat TS 40. Note that the particles are agglomerated but manufactured and tempered to represent rather solid $\mathrm{TiO}_{2}$ particles 
Table 2 Measured particle velocities for the selected parameter sets

Spray parameters

Average particle velocity, $\mathrm{m} / \mathrm{s}$

\begin{tabular}{ll}
\hline $200{ }^{\circ} \mathrm{C}, 30$ bar & $590 \pm 49$ \\
$400{ }^{\circ} \mathrm{C}, 30$ bar & $661 \pm 47$ \\
$600{ }^{\circ} \mathrm{C}, 40 \mathrm{bar}$ & $713 \pm 60$ \\
$800^{\circ} \mathrm{C}, 40 \mathrm{bar}$ & $833 \pm 66$ \\
\hline
\end{tabular}

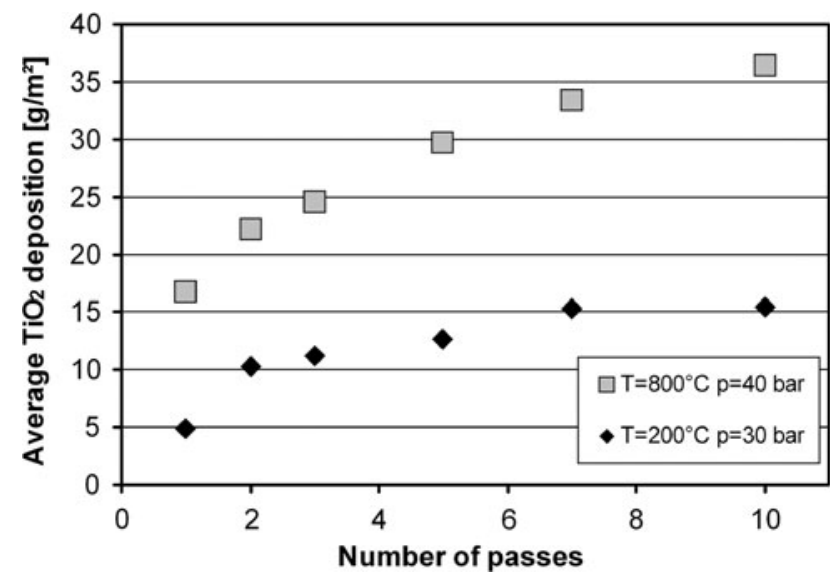

Fig. 2 Mass gain for increasing numbers of spray passes on AlMg3 substrate for a low velocity and a high velocity parameter set

deposition efficiency drops. Deposition efficiency and surface load rise with higher spray temperature and pressure.

The results from investigating the mass gain of anatase $\mathrm{TiO}_{2}$ coatings demonstrate that the deposition reaches a saturation limit. The amount of this limit is-at least for softer substrates as AlMg3 - dependant on spray conditions, leading to more deposited $\mathrm{TiO}_{2}$ for harsher spray parameters. The maximum limit of deposited $\mathrm{TiO}_{2}$ appears to be at roughly $15 \mathrm{~g} / \mathrm{m}^{2}$ for slower particles (average particle velocity $590 \mathrm{~m} / \mathrm{s}$ ) at low temperature conditions, and $>36 \mathrm{~g} / \mathrm{m}^{2}$ for the faster particles at an average particle velocity of $833 \mathrm{~m} / \mathrm{s}$. For analyzing the influence of increasingly harsher spray conditions on the deposition of $\mathrm{TiO}_{2}$ in more detail, the deposition efficiency during the first pass of the spray gun was investigated for different spray temperatures and pressures (Fig. 3). The deposition efficiency is steeply rising with process gas temperatures and is higher for increased pressures.

For a better understanding of the bonding process, also the influence of different substrate materials was investigated. Figure 4 shows the mass gain of $\mathrm{TiO}_{2}$ on stainless steel and titanium substrates for cold spraying with a gas pressure of 40 bars and a gas temperature of $800{ }^{\circ} \mathrm{C}$, respectively. For harder substrate materials, less $\mathrm{TiO}_{2}$ can be deposited and the saturation limit is reached at a smaller number of passes. The curves for both, the titanium and the stainless steel substrates, reach a steady state level already after 1-2 passes and do not rise significantly

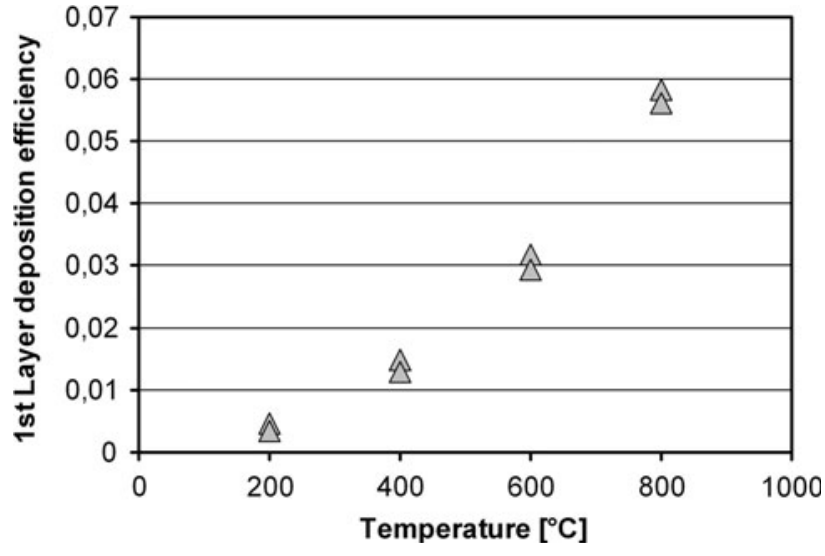

Fig. 3 First layer deposition efficiency of cold spraying $\mathrm{TiO}_{2}$ on Al-substrates for different process gas temperatures and pressures. The graph indicates a steep rise for increasingly harsher spay conditions ( $p=30$ bar for 200 and $400{ }^{\circ} \mathrm{C}$ and $p=40$ bar for 600 and $\left.800{ }^{\circ} \mathrm{C}\right)$

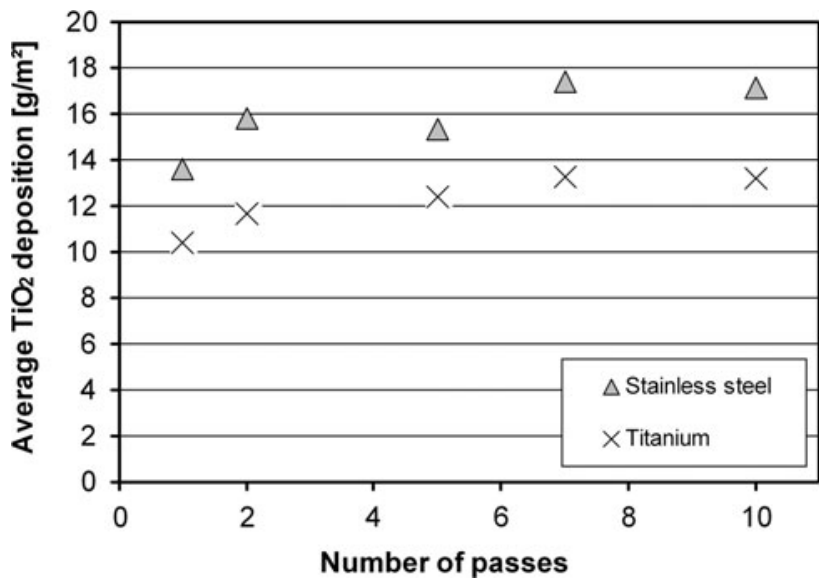

Fig. 4 Mass gain for increasing numbers of spray passes for stainless steel and titanium at $T=800{ }^{\circ} \mathrm{C}$ and $p=40$ bar

afterward. Note that the stagnation level is different for the different materials. The substantial difference, particularly for using substrate materials with different hardness, requests further investigation.

To gain more detailed information, the deposition efficiency during spraying one layer of $\mathrm{TiO}_{2}$ onto different substrate materials is compared in Fig. 5. On the softer aluminum alloy and copper substrates, higher deposition efficiencies are obtained than on the harder stainless steel and titanium substrates. As shown by the correlation of deposition efficiency with Vickers hardness (Fig. 6), the amount of deposited brittle $\mathrm{TiO}_{2}$ is mostly determined by the deformability of the substrate material.

\subsection{Coating Microstructures and Impact Morphologies}

Figure 7 shows typical SEM micrographs of coldsprayed $\mathrm{TiO}_{2}$ layers on $\mathrm{AlMg}$. The substrate is heavily 


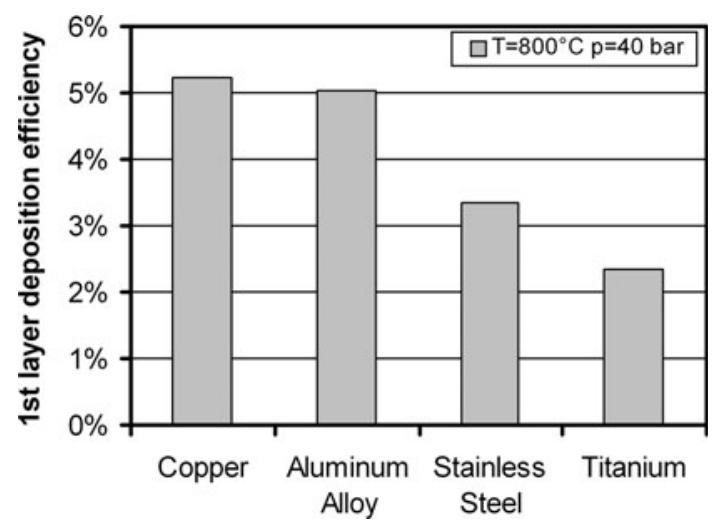

Fig. 5 Deposition efficiency after the first pass of the spray gun for different substrate materials

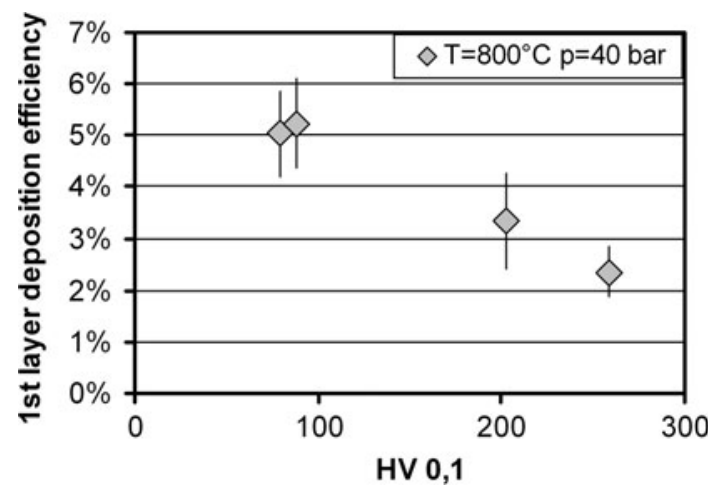

Fig. 6 Deposition efficiency during the first pass of the spray gun over Vickers hardness of the substrate material

deformed and all of the impacted particles show cracks. In particular, later impacting particles to a high extent fracture on the already deposited layers. This can be inferred by comparing microstructures with 1 and 10 spray passes in Fig. 7 that show very similar layer formation. There is no continuous $\mathrm{TiO}_{2}$ coating on the substrate. Despite the small differences, the evaluation of the $\mathrm{TiO}_{2}$ deposition showed a mass gain after applying a higher number of passes.

The different bonding mechanisms for soft and hard substrates can be investigated by comparing single particle impact morphologies in so called "wipe tests." The SEM images in Fig. 8 reveal the different underlying particle bonding processes. Figure 8 shows single particle impacts for identical spray conditions of $\mathrm{TiO}_{2}$ on $\mathrm{AlMg} 3$ and stainless steel. The AlMg3 substrate shows deep impact craters by deformation. An impacted particle is broken in a cone-like manner and sticks in the center of the cavity. On the steel substrate, there is hardly any impact deformation. The impacting particle is also broken but there are only small remnants of the $\mathrm{TiO}_{2}$ particle left at the edges of the impact spot, while the center of the impact spot remains free of $\mathrm{TiO}_{2}$. The round ring-like shape of attached $\mathrm{TiO}_{2}$ with diameters close to the particle size is common for such particle impacts (Fig. 9).
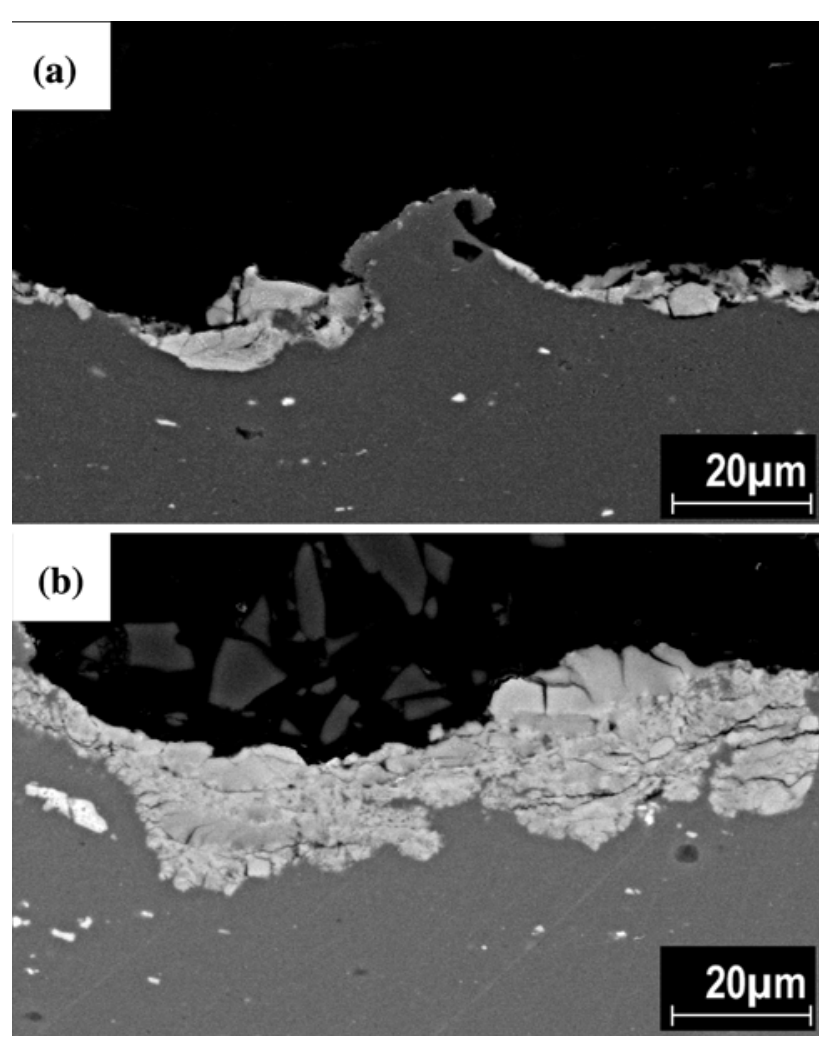

Fig. 7 SEM images of cold-sprayed $\mathrm{TiO}_{2}$ coatings on $\mathrm{AlMg} 3$ substrate. (a) Sprayed as one pass with $800{ }^{\circ} \mathrm{C}$ process gas temperature and 40 bar pressure and (b) sprayed with 10 passes under the same process parameters

Figure 10(a) shows a TEM micrograph of the powder feedstock. The microstructure is nanocrystalline as can be seen in the dark-field images, where each bright spot represents an individual grain. Hence, the grain size is not larger than about $20 \mathrm{~nm}$. The micro- and nanostructure of the coating in Fig. 10(b) reveals that the cold-sprayed particles still show the nanocrystalline structure of the initial particles. Even close to the bonding zone where the highest temperatures in the process would be expected, there is no growth in grain size, as can be observed in Fig. 11. The larger bright spots in Fig. 11, indicating larger crystals, stem from the aluminum alloy substrate while the typical nanocrystalline structure of the $\mathrm{TiO}_{2}$ can be seen in the middle of the micrograph.

\subsection{Crystallographic Coating Structures}

Figure 12 shows the intensities obtained in Raman shift spectroscopy of a pure rutile crystal, the feedstock $\mathrm{TiO}_{2^{-}}$ anatase powder and a cold-sprayed coating. The results demonstrate that rutile and anatase can be clearly distinguished by their individual patterns in the Raman spectrum. The sprayed coating shows the pattern of pure anatase structure. Even for multiple passes with maximum conditions $\left(800{ }^{\circ} \mathrm{C}\right.$ gas temperature and 40 bar pressure) no phase transition to rutile is observable. 

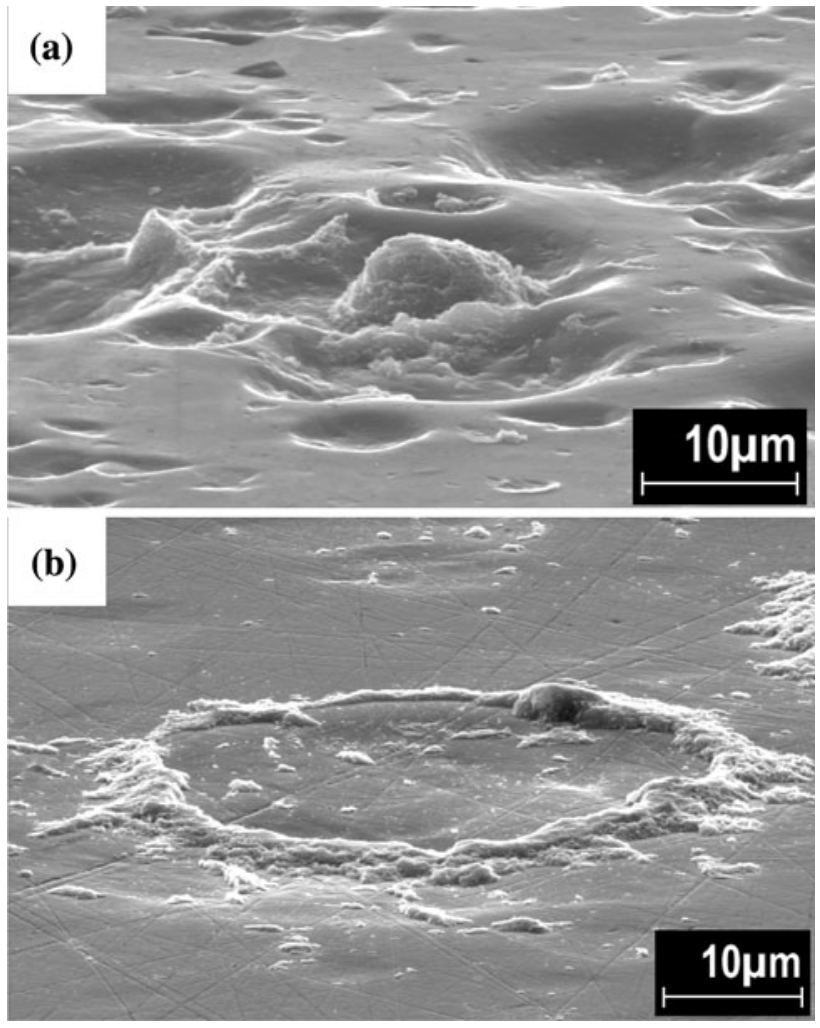

Fig. 8 Single impact morphologies of $\mathrm{TiO}_{2}$ particles on $\mathrm{AlMg} 3$ (a) and on stainless steel (b), sprayed at $T=800{ }^{\circ} \mathrm{C}$ and $p=40$ bar. Note that only small remnants of the initial round $\mathrm{TiO}_{2}$ particles remain on the surface of the metal

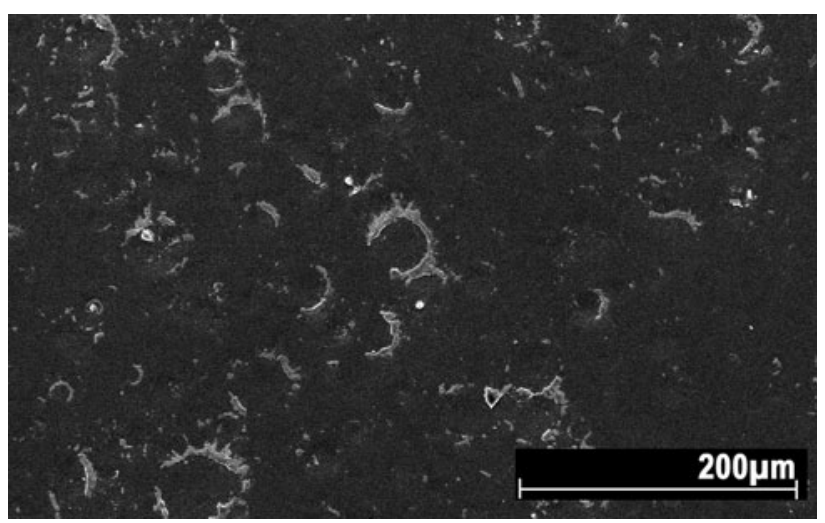

Fig. 9 Top view morphology of several $\mathrm{TiO}_{2}$ single particle impacts on stainless steel. The ring-like shape of the remaining $\mathrm{TiO}_{2}$ is the dominant pattern in this case

\section{Discussion}

The fact that all particles break on impact demonstrates the brittleness of the spray powder under cold spray conditions. The round, ring-like remnants on the metal surface as seen in Fig. 9 resemble the bonding zone of the shear instability that was proposed by Assadi et al. (Ref 2) and experimentally proven by Schmidt et al. (Ref 3$)$ : the

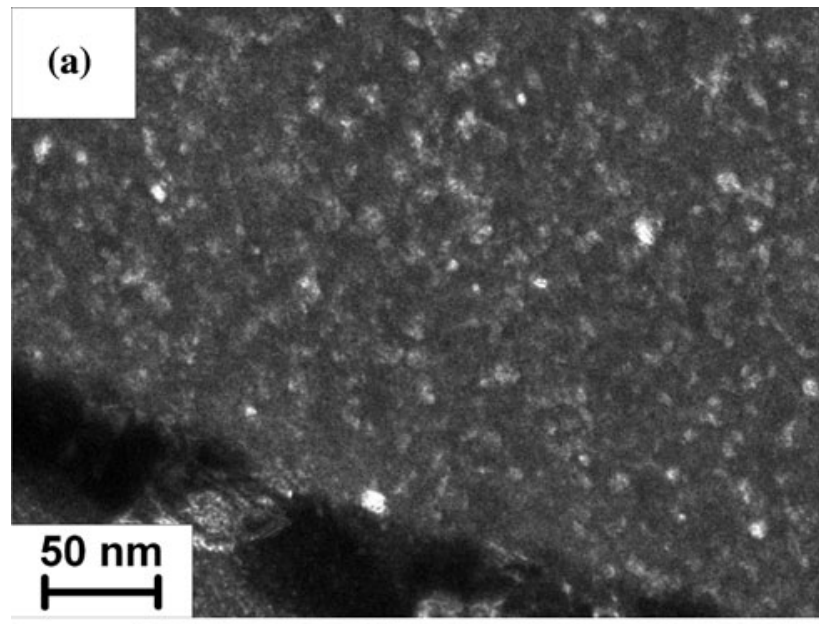

(b)

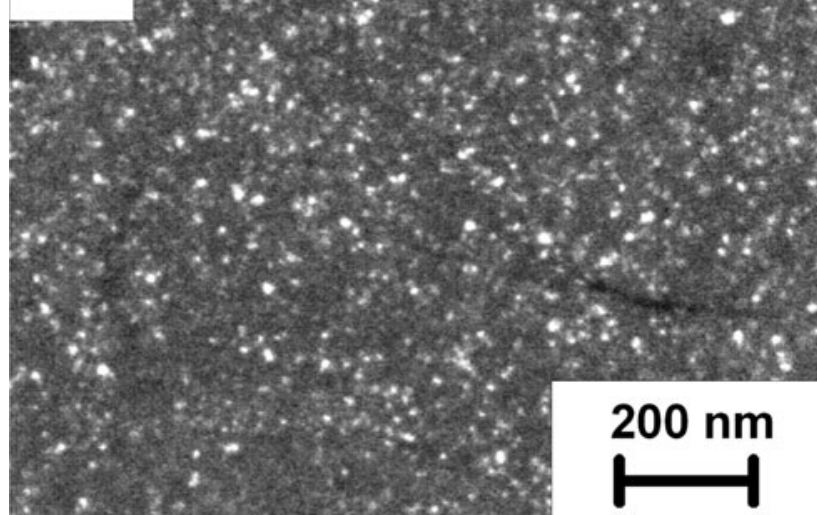

Fig. 10 TEM micrographs of (a) the initial powder and (b) of the as-sprayed titanium dioxide coating $\left(T=800^{\circ} \mathrm{C}, p=40 \mathrm{bar}\right.$, substrate $\mathrm{AlMg} 3$ )

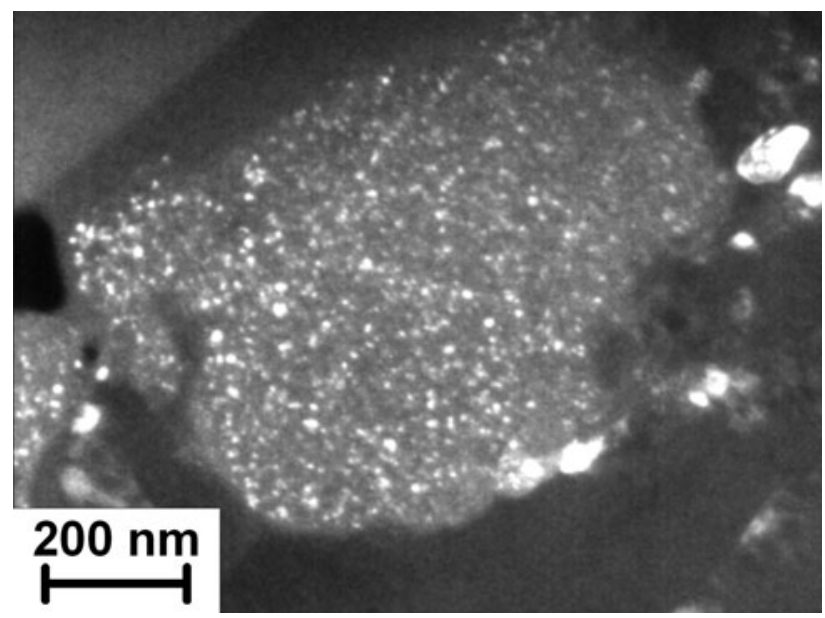

Fig. 11 Bonding zone between $\mathrm{TiO}_{2}$ and the substrate: the AlMg3 substrate is located in the lower right corner. The middle of the image shows the nanocrystalline structure of a bonded $\mathrm{TiO}_{2}$ particle (spray conditions: $T=800{ }^{\circ} \mathrm{C}, p=40$ bar, substrate AlMg3) 


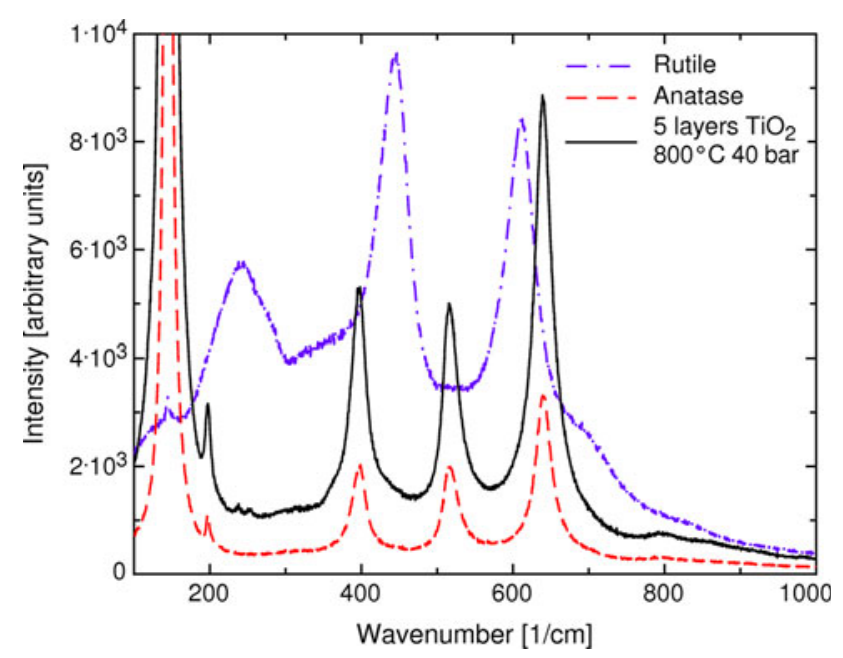

Fig. 12 Raman shift of a $\mathrm{TiO}_{2}$ coating sprayed with five passes at $800{ }^{\circ} \mathrm{C}$ and 40 bar. For comparison, the Raman shift spectra of pure rutile and anatase have been added

south pole region does not contribute to bonding (south pole effect) while only a small circular area, where the shear instability is created, holds the particle. For metallic particles, this bonding zone and the cohesive forces of the particle are strong enough to hold the full particle. In the case of this $\mathrm{TiO}_{2}$ powder, the rest of the particles just seems to have broken off after impact due to the elastic stresses and the respective rebound. If the particles would immediately break into a cloud of splinters that enter the substrate to stick mechanically without a shear instability, we would find a "cloud-like" particle imprint (see Fig. 13a) rather than the ring-shaped remnants. The fact that the center of the impact is indented and free of remnants, i.e., a south pole region under the impacting particle, demonstrates that the particles interact as whole particles instead of a breaking agglomerate (Fig. 13b). Therefore, the shear instability induced in the ductile substrate on impact seems to act for this particular powder as the binding mechanism between $\mathrm{TiO}_{2}$ and the substrate.

The plastic deformation, that is needed for the shear instability to arise, needs to derive from the ductile substrate. This explains why there seems to be a saturation limit for the deposition of the ceramic on the metal substrate, as seen in Fig. 2 and 4: once the surface is covered with $\mathrm{TiO}_{2}$, there is no further ductile component in direct contact to impacting particles. Thus, no shear instability can evolve to bond further impacting particles. The chemical bonding that has been observed by other authors (Ref 10-12) does not seem to have occurred for the rather solid particles in this study. Mechanical entanglement does not seem to be sufficient as well, since a thicker ceramic coating did not build up, no matter what spray conditions were used. However, chemical bonding cannot be ruled out completely since it would depend largely on the nanostructure and respective powder properties. It was proposed that the build-up of thicker coatings is due to breaking up crystallites and thus creating dangling bonds (Ref 16). If the impact energy in our case is dissipated by
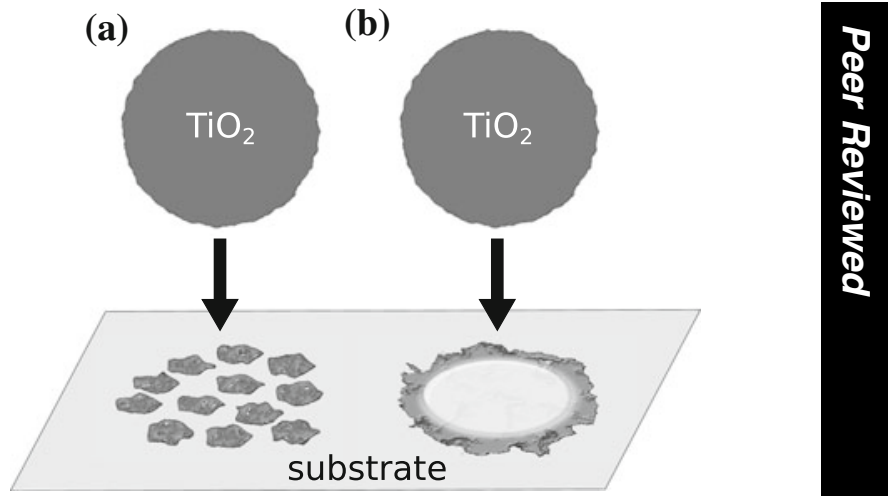

Fig. 13 Schematic drawing of different bonding scenarios: (a) represents bonding by mechanical entanglement, (b) depicts a typical bonding zone of shear instability bonding

merely splitting the particles along the grain boundaries, there might not be enough chemical energy to result in a coating build-up.

Although the impacting particles seem not to bond to deposited ceramic layers, an increasing coating thickness could be observed for the aluminum substrate (Fig. 2), but not for the harder substrate materials as stainless steel and titanium (Fig. 4). The reason for this could be the different impact characteristics: at a similar impact momentum, jetting of substrate material is more pronounced for softer than for harder metals. Thus, by drawing out more substrate material softer substrates can locally supply fresh metal surfaces even after a couple of passes. Figure 7(b) shows an example of a coating, where parts of the aluminum substrate are embedded in-between the $\mathrm{TiO}_{2}$ particles. Sequences of a possible model process are probably as follows: (i) the ceramic particles impact and deform the substrate material, (ii) the shear instability leads to jetting which forms fresh metallic surfaces, in some case even on top of neighboring, already impacted ceramic particles in the close vicinity. (iii) These new metallic surfaces show plastic deformation under following impacts and are able to bond further incoming particles with shear instabilities. This process would be impossible for harder substrates, where the impacting particles do not reach the momentum necessary to deform the substrate significantly, as for stainless steel as shown in Fig. 8(b). If the growth in layer thickness on the AlMg3 substrate were due to bonding between ceramic particles, we should see an increase in layer thickness also for the titanium and steel substrates with more and more spray gun passes. This is, however, not the case. Burlacov et al. (Ref 17) reported similar effects of jetted substrates acting as a binder by cold spraying $\mathrm{TiO}_{2}$ on thermoplastic polysulfone material. The authors describe that softened polymer was acting as an additional binding agent to allow to form subsequent layers of $\mathrm{TiO}_{2}$, similar to the embedded aluminum that can be seen in Fig. 7(b) in the present study. In another study by Yang et al. (Ref 18), a similar upper limit for the deposition of $\mathrm{TiO}_{2}$ with cold spraying on metals has formed, above which no further increase in 
layer thickness is possible, even though using an agglomerated, nanoporous powder.

There is further evidence that the bonding of $\mathrm{TiO}_{2}$, even for the hard metal substrates, needs to arise from substrate deformation: the TEM images as well as the Raman spectroscopy results (Fig. 10-12) showed clearly that the $\mathrm{TiO}_{2}$ crystals remained unchanged during the process. Even at the very edge of the boundary layer between substrate and particle, where the highest temperatures are to be expected, no thermal influence on the $\mathrm{TiO}_{2}$, like, e.g., crystal growth, was visible (Fig. 11). Therefore, the particle impact temperature, which is an important factor for metal-metal coatings, does not seem to play a role in this case, except for heating the substrate to make it more ductile. For all types of metallic substrates, the impact velocity is the decisive factor for enhancing jetting and embedding more $\mathrm{TiO}_{2}$ particles explaining the deposition efficiency increase in Fig. 3.

An interesting aspect is the negative correlation between substrate hardness and deposition efficiency during the first pass of the spray gun. Schmidt et al. (Ref 3) have shown that the critical velocity is the decisive value to determine whether a significant deposition occurs in the cold spray process for metal-metal coatings. The critical velocity is rising with $\mathrm{HV}$ as well, just as in our case, where less material was deposited at harder substrates. In the present case, the spray particles, although showing a similar or lower hardness as compared to the substrates, do not build up thick coatings because of their brittleness.

\section{Conclusions}

The results show that bonding in cold gas spraying of ceramics like $\mathrm{TiO}_{2}$ can be realized by ductile substrates that allow shear instabilities to happen. $\mathrm{TiO}_{2}$ particles interact as solid spheres with the substrate bonding in a ring-like zone. Due to fracture under the elastic rebound forces, the brittle spray particles break and only small remnants remain in the bonding zones. In the present case, the ceramic spray particles did not contribute to bonding and therefore could not build up layers on their own, i.e., with impacts that hit another ceramic particle rather than the substrate surface. Only if substrate material is brought to the surface and is available to bind other particles, a second layer or parts of it are likely to be attached to the coating on impact, as it was the case for AlMg3 in this study. Causing more severe deformation of the substrate, higher particle velocities increase the deposition efficiency and also the saturation limit for the deposited $\mathrm{TiO}_{2}$.

\section{Acknowledgments}

The authors would like to thank the laboratory staff, in alphabetical order Thomas Breckwoldt, Dieter Müller, Norbert Németh, Camilla Schulze, Matthias Schulze, and Uwe Wagener for their support in the presented work.
This work was funded by the German Research Foundation (Deutsche Forschungsgemeinschaft, DFG).

\section{References}

1. A.P. Alkhimov, V.F. Kosarev, and A.N. Papyrin, A Method of Cold Gas-Dynamic Deposition, Sov. Phys. Dokl., 1990, 35(12), p 1047-1049 (in Russian, Transl: American Inst. of Phys., 1991)

2. H. Assadi, F. Gartner, T. Stoltenhoff, and H. Kreye, Bonding Mechanism in Cold Gas Spraying, Acta Mater., 2003, 51(15), p 4379-4394

3. T. Schmidt, F. Gartner, H. Assadi, and H. Kreye, Development of a Generalized Parameter Window for Cold Spray Deposition, Acta Mater., 2006, 54(3), p 729-742

4. T. Schmidt, H. Assadi, F. Gartner, H. Richter, T. Stoltenhoff, H. Kreye, and T. Klassen, From Particle Acceleration to Impact and Bonding in Cold Spraying, J. Thermal Spray Technol., 2009, 18(5-6), p 794-808

5. S. Marx, A. Paul, A. Köhler, and G. Hüttl, Cold Spraying: Innovative Layers for New Applications, J. Thermal Spray Technol., 2006, 15(2), p 177-183

6. H.Y. Lee, S.H. Jung, S.Y. Lee, Y.H. You, and K.H. Ko, Correlation Between $\mathrm{Al}_{2} \mathrm{O}_{3}$ Particles and Interface of $\mathrm{Al}-\mathrm{Al}_{2} \mathrm{O}_{3}$ Coatings by Cold Spray, Appl. Surf. Sci., 2005, 252(5), p 18911898

7. G. Bae, Y. Xiong, S. Kumar, K. Kang, and C. Lee, General Aspects of Interface Bonding in Kinetic Sprayed Coatings, Acta Mater., 2008, 56(17), p 4858-4868

8. C.J. Li, G.J. Yang, X.C. Huang, W.Y. Li, and A. Ohmori, Formation of $\mathrm{TiO}_{2}$ Photocatalyst Through Cold Spraying, Thermal Spray 2004: Advances in Technology and Application, May 10-12, 2004 (Osaka, Japan), ASM International, 2004, p 315-319

9. J. Han, S.W. Lee, E.A. Lee, T. Xiong, Z. Bao, and H. Du, Photocatalytic Properties of $\mathrm{TiO}_{2}$ Coatings Prepared by Cold Spray Process, Mater. Sci. Forum, 2006, 510-511, p 130-133

10. J. Akedo, Aerosol Deposition of Ceramic Thick Films at Room Temperature: Densification Mechanism of Ceramic Layers, J. Am. Ceram. Soc., 2006, 89(6), p 1834-1839

11. S.Q. Fan, G.J. Yang, C.J. Li, G.J. Liu, C.X. Li, and L.Z. Zhang, Characterization of Microstructure of $\mathrm{Nano}^{-\mathrm{TiO}_{2}}$ Coating Deposited by Vacuum Cold Spraying, J. Thermal Spray Technol., 2006, 15(4), p 513-517

12. M. Yamada, Y. Kandori, S. Kazunori, and M. Fukumoto, Fabrication of Titanium Dioxide Photocatalyst Coatings by Cold Spray, J. Solid Mech. Mater. Eng., 2009, 3(2), p 210-216

13. A. Fujishima and K. Honda, Electrochemical Evidence for the Mechanism of the Primary Stage of Photosynthesis, Bull. Chem. Soc. Jpn., 1971, 44, p 1148-1150

14. H. Gutzmann, J.-O. Kliemann, R. Albrecht, F. Gärtner, T. Klassen, F.-L. Toma, L.-M. Berger, and B. Leupolt, Evaluation of the Photocatalytic Activity of $\mathrm{TiO}_{2}$-Coatings Prepared by Different Thermal Spray Techniques, Proc. ITSC 2010, Thermal Spray: Global Solutions for Future Applications, May 3-5, 2010 (Singapore), DVS-Berichte 264, DVS Media GmbH, Düsseldorf, Germany (on CD), 2010, p 187-191

15. Matweb.com (August 13th 2010)

16. M. Yamada, H. Isago, K. Shima, H. Nakano, M. Fukumoto, and J. Toyohashi, Deposition of $\mathrm{TiO}_{2}$ Ceramic Particles on Cold Spray Process, Proc. ITSC 2010, Thermal Spray: Global Solutions for Future Applications, May 3-5, 2010 (Singapore), DVSBerichte 264, DVS Media GmbH, Düsseldorf, Germany (on CD), 2010, p 187-191

17. I. Burlacov, J. Jirkovsky, L. Kavan, R. Ballhorn, and R.B. Heimann, Cold Gas Dynamic Spraying (CGDS) of $\mathrm{TiO}_{2}$ (Anatase) Powders Onto Poly(Sulfone) Substrates: Microstructural Characterisation and Photocatalytic Efficiency, J. Photochem. Photobiol. A, 2007, 187, p 285-292

18. G.J. Yang, C.-J. Li, F. Han, W.-Y. Li, and A. Ohmori, Low Temperature Deposition and Characterization of $\mathrm{TiO}_{2}$ Photocatalytic Film Through Cold Spray, Appl. Surf. Sci., 2008, 254, p 3979-3982 